\title{
Should Gastric Decompression Be a Routine Procedure in Patients Who Undergo Pylorus-Preserving Pancreatoduodenectomy?: Reply
}

\author{
Joon Seong Park ${ }^{1} \cdot J_{a e}$ Young Kim ${ }^{1} \cdot J^{2 e}$ Keun Kim ${ }^{1} \cdot$ Dong Sup Yoon ${ }^{1}$
}

Published online: 28 February 2017

(c) Société Internationale de Chirurgie 2017

To the Editors,

We would like to thank Dr. Tez for his interest in our article "Should gastric decompression be a routine procedure in patients who undergo pylorus-preserving pancreatoduodenectomy (PPPD)?" [1]. We agree that some patients after PPPD require nasogastric(NG) tube, and NG tube has been used following gastrointestinal anastomoses for several years.

But, nowadays, recently published data support the abandonment of routine NG tube for elective abdominal surgical procedures [2-4]. Actually in our data [1], only $9.8 \%$ of patients in the no-tube gastrostomy group required eventual nasogastric insertion because of delayed gastric emptying.

We agree that changing the clinical habit is harder than changing sleeping habits because implementing changes in clinical process is usually not a single action but involves a well-planned stepwise process. Change can frequently be messy, waste time and can have unpredicted consequences. However, the use of an evidence-based approach enables us to do the changes in our clinical habits, and it allows us to constantly review our practice and to seek new and more effective ways of our clinical pathways.
In conclusion, surgeons must be active in promoting evidence-based practice and focusing on changing competences and attitude to translating evidence to practice for better surgical outcomes.

\section{References}

1. Park JS, Kim JY, Kim JK et al (2016) Should gastric decompression be a routine procedure in patients who undergo pyloruspreserving pancreatoduodenectomy? World J Surg 40:2766-2770. doi:10.1007/s00268-016-3604-0

2. Nelson R, Edwards S, Tse B (2007) Prophylactic nasogastric decompression after ab-dominal surgery. Cochrane Database Syst Rev 3:CD004929

3. Rao W, Zhang X, Zhang J et al (2011) The role of nasogastric tube in decompression after elective colon and rectum surgery: a metaanalysis. Int J Co-lorectal Dis 26:423-429

4. Kunstman JW, Klemen ND, Fonseca AL et al (2013) Nasogastric drainage may be unnecessary after pancreaticoduodenectomy: a comparison of routine vs selective decompression. J Am Coll Surg 217:481-488
Joon Seong Park

jspark330@yuhs.ac

1 Pancreatobiliary Cancer Clinic, Department of Surgery, Gangnam Severance Hospital, College of Medicine, Yonsei University, 612 Eunjoro, Gangnam-gu, Seoul 135-720, Korea 